\title{
VIGILÂNCIA E CONTROLE DA QUALIDADE DA ÁGUA DO CÓRREGO PIRAPITINGA NO MUNICÍPIO DE ITUIUTABA (MG)
}

Sergio Marcos Sanches ${ }^{1}$

Silvana Gonçalves Hipólito²

Eny Maria Vieira ${ }^{3}$

Célia Passos ${ }^{4}$

\section{Resumo}

A água destinada ao consumo humano deve preencher as condições mínimas para que possa ser ingerida, o que se consegue através do seu tratamento. 0 presente estudo teve como objetivo analisar e verificar a qualidade da água do Córrego Pirapitinga, da cidade de Ituiutaba (MG), quanto aos parâmetros físicos, químicos e microbiológicos. Foram coletadas amostras de água provenientes de quatro pontos, sendo três no Córrego Pirapitinga e um numa vertente menor a leste. As análises dos metais $\mathrm{Cr}, \mathrm{Cd}, \mathrm{Cu}, \mathrm{Fe}$ e $\mathrm{Pb}$ foram feitas utilizando-se a técnica de Espectroscopia Com Plasma Induzido (ICP-OES); as análises de cor e turbidez foram feitas pelo método espectrofotométrico. Os resultados obtidos de metais, cor, $\mathrm{pH}$, turbidez, temperatura, coliformes fecais e totais foram comparados com os valores estabelecidos pela Resolução 357 do CONAMA, de 2005. Cabe ressaltar que a partir dos resultados obtidos há necessidade de contínuo monitoramento da água do Córrego Pirapitinga - Ituiutaba (MG), quanto à presença dos metais $\mathrm{Cd}$ e $\mathrm{Cr}$, e coliformes fecais e totais.

Palavras-chave: Qualidade da água. Parâmetro físico-químico. Microbiológico. Córrego Pirapitinga.

\section{Introdução}

A água é um componente essencial para a sobrevivência do homem. Ela representa cerca de $70 \%$ do peso do corpo de um ser humano e participa de diversas funções fisiológicas do nosso organismo, como exemplo, a regulagem de temperatura, o transporte de minerais e de outras substâncias para dentro e para fora da célula (NIKAIDO et al., 2009).

Segundo a Organização Mundial da Saúde (OMS), cerca de $80 \%$ das doenças que ocorrem em países em desenvolvimento são veiculadas pela água contaminada por micro-organismos patogênicos (COELHO et al. , 2007). Isto se deve ao fato de apenas 30\% da população mundial ter água tratada e os outros $70 \%$ terem poços como fonte de água, facilitando assim a sua contaminação (FERNANDEZ; SANTOS, 2007). A contaminação da água pode se dar em função da descontinuidade do fornecimento, da falta de rede de esgoto, da manutenção inadequada da rede e reservatórios, agrotóxicos e aterros sanitários, que contaminam os lençóis freáticos (SOARES et al., 2002; BETTEGA et al., 2006).

De acordo com Brito et al. (2005) o consumo mundial de água aumentou seis vezes em menos de um século, correspondendo a mais que o dobro da população mundial. A análise da água pode evidenciar o

\footnotetext{
${ }^{1}$ Professor Doutor do Instituto Federal de Educação, Ciência e Tecnologia do Triangulo Mineiro - Campus Ituiutaba. Ituiutaba, Minas Gerais, Brasil.sergiosanches@iftm.edu.br. (34)91753704. Rua Belarmino Vilela Junqueira s.n. ${ }^{\circ}$, Bairro Novo Tempo 2, Ituiutaba, Minas Gerais, CEP 38305-200.

${ }^{2}$ Graduada em Zootecnia, Aluna do Curso de Agroindústria, Instituto Federal de Educação, Ciência e Tecnologia - Campus Ituiutaba. Ituiutaba, Minas Gerais, Brasil.silvanagbr@yahoo.com.br. (34) 96565115. Rua Vinte Três, 1791, Centro, Ituiutaba, Minas Gerais, CEP 38300114.

${ }^{3}$ Professora e Pesquisadora do Instituto de Química de São Carlos. São Carlos, São Paulo, Brasil. eny@iqsc.usp.br. (16) 33739446. Avenida Trabalhador São Carlense, 400, centro, São Carlos, São Paulo, CEP 13560-970, Caixa Postal:780.

${ }^{4}$ Aluna do curso Bacharelado em Química, Universidade Federal de Uberlândia - Campus Pontal - Ituiutaba, Minas Gerais, Brasil. sellyap@qui.pontal.ufu.br. (34) 97931920. Rua Vinte, 1600, Bairro Tupã, CEP 38304-402.
} 
uso inadequado do solo, os efeitos do lançamento de efluentes, suas limitações de uso e seu potencial de autodepuração (VON SPERLING, 2005). Dentre os parâmetros utilizados para avaliar a qualidade da água estão os físicos, químicos e os microbiológicos.

O córrego Pirapitinga foi escolhido para a avaliação da qualidade de sua água baseados em critérios antropogênicos, ou seja, locais onde há presença de ações humana sobre o mesmo. Devido ao crescimento acelerado ocorreram problemas típicos urbanos, como desordenamento territorial, a falta de estrutura, o aumento da produção de lixo, a expansão da área urbana em direção as áreas preservadas.

Ele tem a sua nascente no território do Instituto Federal de Educação, Ciência e Tecnologia do Triângulo Mineiro (IFTM), e está localizado no município de Ituiutaba. O município é banhado por duas grandes bacias hidrográficas, a do Rio da Prata, no setor sul do município, e a do Rio Tijuco como principal fornecedora de água cortando o munícipio de leste a oeste. Este córrego percorre a área rural de Ituiutaba até adentrar na parte urbana do município, onde recebe águas de outras vertentes menores até o seu encontro com o Rio Tijuco.

Diante dos diversos aspectos que estão degradando os recursos hídricos, o presente estudo teve como objetivo analisar e verificar a qualidade da água do Córrego Pirapitinga, de forma a impedir problemas decorrentes da poluição da água que venham comprometer seu aproveitamento múltiplo e integrado, colaborando para minimização dos impactos negativos ao meio ambiente, e também a saúde pública.

\section{Material e método}

\section{1- Pontos de coleta das amostras de água no córrego Pirapitinga.}

O presente estudo foi realizado em uma pequena área ao sul da parte urbana do município nas mediações do Instituto Federal de Educação, Ciência e Tecnologia do Triângulo Mineiro, Campus Ituiutaba (IFTM).

Dentro da área de estudo foram selecionados quatro pontos, sendo que o Ponto 1 nas proximidades do Córrego com o primeiro grande bairro da cidade, e com um pequeno lixão, o Ponto 2 na ponte em construção para acesso ao IFTM, o Ponto 3 na atual ponte de acesso ao IFTM, e o Ponto 4 encontra-se na nascente do Córrego. O Córrego Pirapitinga é classificado segundo a Resolução CONAMA 357 como classe 2. Na Figura 1, e na Tabela 1 encontram-se os pontos amostrados.

Tabela1. Localização dos pontos de coletas do Córrego Pirapitinga - Ituiutaba (MG).

\begin{tabular}{l|c|c}
\hline Pontos de coletas das & \multicolumn{2}{|c}{ Coordenadas } \\
$\begin{array}{l}\text { amostras de água do Córrego } \\
\text { Pirapitinga - Ituiutaba -MG }\end{array}$ & $\mathbf{0}$ & S \\
\cline { 2 - 3 } & & $19.0081^{\circ}$ \\
\hline 1 & $49.4763^{\circ}$ & $19.00617^{\circ}$ \\
\hline 2 & $49.47561^{\circ}$ & $19.01355^{\circ}$ \\
\hline 3 & $49.48082^{\circ}$ & $19.02815^{\circ}$ \\
\hline 4 & $49.48301^{\circ}$ & 19.0 \\
\hline
\end{tabular}

Fonte: Elaboração dos autores. 


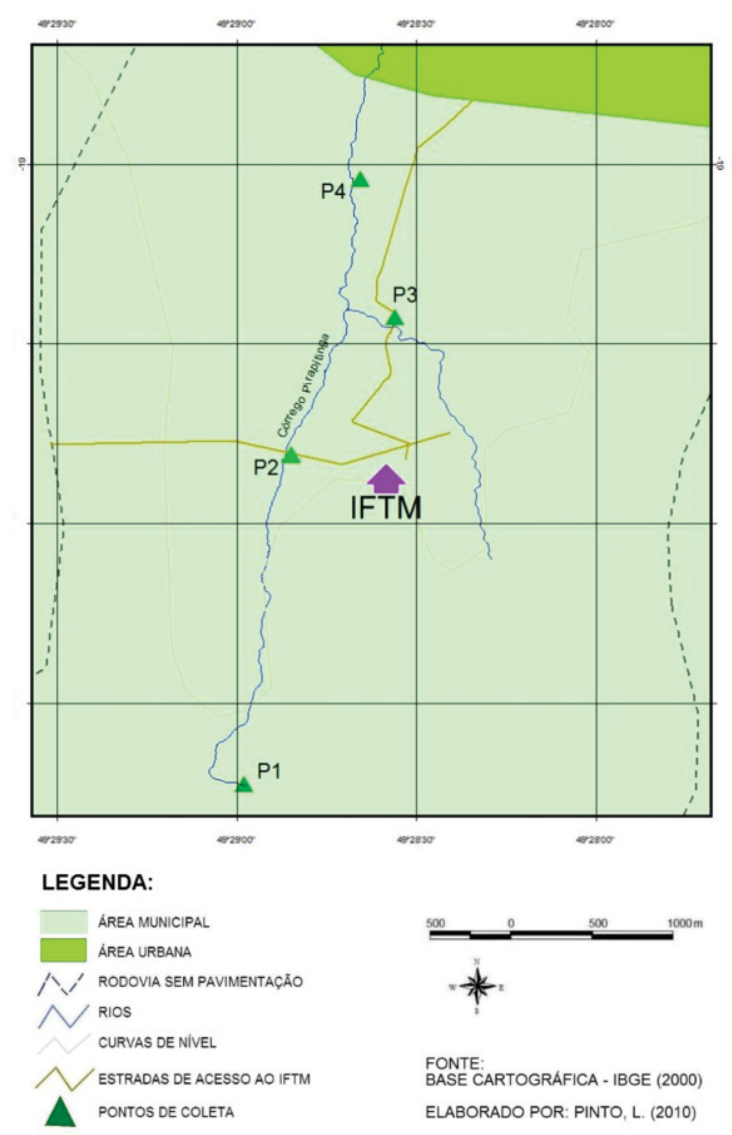

Figura 1. Localização dos quatros Pontos de Coleta no Córrego Pirapitinga no município de Ituiutaba (MG).

Fonte: Elaboração dos autores.

Para este estudo as amostras de água foram coletadas no período de março de 2012 a novembro de 2012, correspondendo aos períodos de seca, chuva e períodos intermediários.

\section{2- Amostragem de água do córrego Pirapitinga para a análise de metais, cor aparente, turbidez e pH}

Coletaram-se amostras de água em cada ponto selecionado conforme Tabela 1 e Figura 1. Devido o córrego possuir uma largura em torno de três metros, foram realizadas amostragens simples. Realizaramse três coletas, nos dias 27/03/2012, 01/07/2012 e 05/11/2012, sendo as amostras utilizadas para a determinação de metais, turbidez, cor aparente e $\mathrm{pH}$. Os volumes coletados para cada parâmetro seguiram os procedimentos do "Standard Methods for the Examination of Water ands Wastewater" (APHA, 1998).

A água do próprio local foi utilizada para ambientar os frascos, de modo a minimizar possíveis interferências; e em seguida preenchidos com as amostras, devidamente acondicionadas em caixa de poliestireno e levadas ao Laboratório de Química. As amostras de água coletadas para a determinação de metais foram acidificadas com ácido nítrico supra-puro até $\mathrm{pH} 2$, sendo mantidas refrigeradas até análise. A medida do pH foi feita no próprio local, e as análises de cor aparente e turbidez feitas no dia da coleta.

\section{3 - Digestão das amostras de água para a determinação de metais}

Para a realização da digestão das amostras de água para a determinação de metais transferiram-se alíquotas de $100 \mathrm{~mL}$ de água, medida em balão volumétrico, para os tubos do bloco digestor, aos quais foram adicionados $2 \mathrm{~mL}$ de $\mathrm{HNO}_{3}$ e $5 \mathrm{~mL}$ de $\mathrm{HCl}$. Elevou-se a temperatura a $95^{\circ} \mathrm{C}$ e manteve-se $\mathrm{o}$ aquecimento até que o volume da amostra fosse reduzido a $15 \mathrm{~mL}$, sob-refluxo. Após resfriamento, as amostras foram transferidas para um balão volumétrico de $50 \mathrm{~mL}$, completando-se então seu volume com água Milli-Q. A amostra foi filtrada e mantida a $4{ }^{\circ} \mathrm{C}$ até a realização da análise. Esse método segue o procedimento do método 3005A da Environmental Protection Agency (USEPA, 1992) para as análises dos metais. 


\subsection{Construção das curvas analíticas para a determinação de metais em água}

As curvas analíticas foram preparadas com três pontos mais o branco, sendo que cada ponto foi preparado em triplicata, a partir de solução estoque, cuja concentração exata é de $1000 \mathrm{mg} \mathrm{L}^{-1}$. As concentrações utilizadas para os metais $\mathrm{Fe}, \mathrm{Cd}, \mathrm{Cr}, \mathrm{Pb}, \mathrm{Cu}$, foram:

$\mathrm{Cr}-0,00 ; 0,50 ; 2,00$ e $4,00 \mathrm{mg} \mathrm{L}^{-1}$;

$\mathrm{Pb}-0,00 ; 0,50 ; 3,00$ e $6,00 \mathrm{mg} \mathrm{L}^{-1}$;

$\mathrm{Cu}-0,00 ; 1,00 ; 3,00$ e $6,00 \mathrm{mg} \mathrm{L}^{-1}$;

Cd- 0,00;0,004;0,03 e 0,06 $\mathrm{mg} \mathrm{L}^{-1}$;

$\mathrm{Fe}-0,00 ; 0,50 ; 2,00$ e $4,00 \mathrm{mg} \mathrm{L}^{-1}$

2.5- Determinação de metais das amostras de água do Córrego Pirapitinga utilizando a técnica de espectroscopia com plasma induzido.

As análises de metais $\mathrm{Cr}, \mathrm{Cd}, \mathrm{Cu}$, Fe e Pb foram feitas na Central de Análise Químicas do Instituto de Química do Campus da USP de São Carlos (SP), em um equipamento de Espectroscopia com Plasma Induzido (ICP-OES), marca PERKIN ELMER, modelo Optima 3000 DV. Os comprimentos de ondas utilizados nas análises de metais e os limites de detecção estão na Tabela 2.

Tabela 2- Comprimento de onda utilizada nas análises de metais, e limites de detecção.

\begin{tabular}{c|c|c}
\hline Metais & $\begin{array}{c}\text { Comprimento de onda } \\
(\mathbf{n m})\end{array}$ & $\begin{array}{c}\text { Limites de detecção } \\
\left(\mu \mathbf{g ~ L}^{-1}\right)\end{array}$ \\
\hline Cromo & 205,560 & $0,1-1,0$ \\
Cádmio & 214,440 & $<1,0$ \\
Cobre & 324,752 & $0,1-1,0$ \\
Ferro & 238,204 & $<0,1$ \\
Chumbo & 220,353 & $0,1-1,0$ \\
\hline
\end{tabular}

Fonte: Elaboração dos autores.

\section{5- Determinação do pH das amostras de água do Córrego Pirapitinga}

As análises de $\mathrm{pH}$ foram feitas no local das coletas utilizando-se um pHmetro da Marca Orion 710A, previamente calibrado com os tampões de valores de $\mathrm{pH}$ 4, 7 e 10. Todas as medidas foram feitas à temperatura ambiente.

\section{6 - Determinações da turbidez das amostras de água do Córrego Pirapitinga}

As análises foram feitas no Laboratório de Química do IFTM - Campus Ituiutaba (MG) em um turbidímetro da marca HACH, modelo 2100 P.

\section{7 - Determinações da cor aparente das amostras de água do Córrego Pirapitinga}

As amostras de água foram analisadas pelo método direto com o uso de um aparelho Colorímetro HACH DR/ 890 Portable Colorimeter.

\section{8 - Determinações das análises de coliformes fecais e totais das amostras de água do Córrego Pirapitinga}

As análises foram feitas na Superintendência de Água e Esgoto (SAE), no Laboratório de Microbiologia de acordo com os procedimentos do "Standard Methods for the Examination of Water ands Wastewater" (APHA, 1998).

O preparo da água de diluição procedeu-se a partir da Solução $\mathrm{A}: 34 \mathrm{~g}$ de $\mathrm{KH}_{2} \mathrm{PO}_{4} \mathrm{PA}$ em $1000 \mathrm{~mL}$ de água deionizada. Foram adicionados 1,25 da Solução $A$ e $5 \mathrm{~mL}$ da Solução B em $1000 \mathrm{~mL}$ de água deionizada. Assim foi preparada a primeira diluição decimal $\left(10^{-1}\right)$, sendo que $1 \mathrm{~mL}$ da mesma diluição 
corresponde a 0,1 mL da amostra, procedendo essa sequência até serem obtidas as diluições desejadas $\left(10^{-1}, 10^{-2}\right.$ e $\left.10^{-3}\right)$.

Com uma pipeta de $5 \mathrm{~mL}$ foi inoculado $1 \mathrm{~mL}$ da amostra em cada um dos tubos correspondentes a essa quantidade de inóculo. Após a inoculação de todos os volumes da amostra ou diluições requeridas para o exame, a estante contendo os tubos inoculados foi armazenada em estufa de cultura $35 \pm 0,5^{\circ} \mathrm{C}$, durante $24 \pm 2 \mathrm{~h}$. Após esse período foi realizada a leitura dos resultados, observando-se coloração, indicativa do desenvolvimento de coliforme total e para a observação de Escherichia Coli foi utilizada uma lâmpada UV de 6 W de potência e 365 nm de comprimento de onda para a confirmação de fluorescência.

\section{Resultados e discussão}

\section{1. $\mathrm{pH}$}

O parâmetro pH se configura como um dos mais importantes com relação ao saneamento ambiental. Ele é amplamente utilizado para a caracterização das águas fluviais, ou efluentes, entre outros. O pH está relacionado à atividade hidrogeniônica, ou seja, a concentração de íons $\left(\mathrm{H}^{+}\right.$e OH$\left.{ }^{-}\right)$, caracterizando a intensidade de ácidos em uma solução.

A Resolução CONAMA 357 de 2005 estabelece para as águas doce de classe 2 valores de pH variando de 6,00 a 9,00. Na Tabela 3 encontram-se os valores de pH das amostras de água coletadas nos pontos de amostragens do Córrego Pirapitinga, município de Ituiutaba (MG).

Tabela 3. Valores de pH medidos na água do Córrego Pirapitinga - Município de Ituiutaba (MG).

\begin{tabular}{c|c|c|c}
\hline \multirow{2}{*}{$\begin{array}{c}\text { Pontos de Coleta } \\
\text { de Amostras de } \\
\text { Água }\end{array}$} & $\begin{array}{c}\mathbf{1 .} \text { a Coleta } \\
\mathbf{2 7 / 0 3 / 2 0 1 2}\end{array}$ & $\begin{array}{c}\mathbf{2 .} .^{\text {a }} \text { Coleta } \\
\mathbf{0 1 / 0 7 / 1 2}\end{array}$ & $\begin{array}{c}\mathbf{3 .}^{\text {a }} \text { Coleta } \\
\mathbf{0 5 / 1 1 / 2 0 1 2}\end{array}$ \\
\hline 1 (IFTM) & 7,29 & 6,71 & 7,30 \\
\hline 2 (Ponte) & 7,40 & 6,89 & 7,44 \\
\hline 3 (Ponte Aterro) & 7,39 & 6,77 & 7,41 \\
\hline 4 (Nascente) & 6,78 & 6,72 & 6,85 \\
\hline
\end{tabular}

Fonte: Elaboração dos autores.

Analisando-se os dados apresentados na Tabela 3 nota-se que os valores de $\mathrm{pH}$ das amostras de água coletadas nos quatro pontos de amostragem variaram entre 7,44 e 6,71. 0 pH altera a solubilidade e, por isso a disponibilidade de muitas substâncias, mas também afeta a toxicidade de substâncias como metais e formas disponíveis de nitrogênio. Todos os valores de $\mathrm{pH}$ medidos estão dentro dos valores estipulados pela Resolução CONAMA n. ${ }^{\circ} 357$ de 2005, que delimita os valores de pH entre 6,00 e 9,00 (BRASIL, 2005).

\subsection{Turbidez}

É definida como uma medida do grau de interferência à passagem da luz através do líquido. A alteração à penetração da luz na água decorre da presença de material em suspensão em estado coloidal, as quais podem apresentar ampla faixa de tamanhos. Essas partículas são constituídas por plâncton, bactérias, argilas, silte em suspensão, fontes de poluição que lançam materiais finos e outros.

A presença dessas partículas provoca a dispersão e a absorção da luz, dando a água uma aparência nebulosa e opaca, indesejável. Na Tabela 4 são apresentados os resultados das medidas de turbidez para as amostras de água coletadas nos pontos de monitoramento do Córrego Pirapitinga. 
Tabela 4. Valores de turbidez em amostras de água coletadas em pontos de amostragem do Córrego Pirapitinga.

\begin{tabular}{|c|c|c|c|}
\hline \multirow{2}{*}{$\begin{array}{c}\text { Pontos de Coleta } \\
\text { de Amostras de } \\
\text { Água }\end{array}$} & \multicolumn{3}{|c|}{$\begin{array}{c}\text { Turbidez } \\
\text { (NTU) }\end{array}$} \\
\hline & $\begin{array}{c}1 .{ }^{a} \text { Coleta } \\
27 / 03 / 2012\end{array}$ & $\begin{array}{l}2 .^{\text {a Coleta }} \\
01 / 07 / 12\end{array}$ & $\begin{array}{c}3 .^{a} \text { Coleta } \\
05 / 11 / 2012\end{array}$ \\
\hline 1 (IFTM) & 6,49 & 31,61 & 39,50 \\
\hline 2 (Ponte) & 7,31 & 39,60 & 24,24 \\
\hline 3 (Ponte Aterro) & 10,1 & 37,23 & 15,00 \\
\hline 4 (Nascente). & 7,11 & 25,02 & 13,00 \\
\hline
\end{tabular}

Fonte: Elaboração dos autores.

Os valores de turbidez obtidos nas análises da água coletada nos quatro pontos de amostragem apresentaram-se na faixa de 6,49 a 39,60. Esses valores mostram que todas as amostras analisadas encontravam-se de acordo com o VMP estabelecidos pela Resolução do CONAMA 357 de 2005 que é 40 NTU.

Pode-se observar que os valores da turbidez para o ponto 4 (Nascente) foram menores em relação aos demais pontos, o que se deve à preservação da mata ciliar. Na segunda coleta o ponto com mais elevado valor medido de turbidez foi o ponto dois, que fica localizado na Ponte, com valores de 39,60 NTU, estando, porém, de acordo com a legislação. O valor alto deve-se provavelmente às características do ponto dois. Não há a presença de mata ciliar, ocorre o manejo inadequado do solo, ausência de curvas de nível em vários trechos, principalmente próximo ao ponto de amostragem.

$\mathrm{Na}$ segunda e terceira coletas de dados, todas as amostras recolhidas se revelaram dentro dos valores estabelecidos pela Resolução CONAMA 357 de 2005, embora alguns pontos apresentassem valores superiores às demais, continuando, todavia, dentro dos valores estabelecidos pela legislação.

Esses valores apresentaram-se relativamente baixos, podendo ser um indicativo de pouco intemperismo das rochas ou de baixa deposição de sedimentos. Segundo Teixeira (2005), a turbidez está diretamente relacionada com o teor de sólidos em suspensão, portanto, a porção de água da amostra do Ponto 4 (nascente) certamente apresentará baixos teores de sólidos em suspensão.

Do ponto de vista sanitário, a turbidez elevada afeta esteticamente os corpos d'água, e encarece 0 tratamento para os diversos usos. Outro fator a ser considerado, relaciona-se com a fauna e a flora, que poderão sofrer distúrbios por conta da redução da entrada da luz (MACÊDO, 2004).

\subsection{Cor aparente}

A cor da água é o resultado dos processos de decomposição que ocorrem no meio ambiente, o que também pode ser devido à presença de alguns íons metálicos como o ferro e o manganês (BRANCO, 1991).

As principais substâncias que ocasionam cor à água são as substâncias húmicas (MACÊDO, 2004). A cor aparente inclui não somente as substâncias, mas também aquela que envolve a matéria orgânica suspensa. Na Tabela 5 estão apresentados os resultados da cor aparente para a água proveniente dos três pontos de abastecimento público do Córrego Pirapitinga, município de Ituiutaba (MG).

Tabela 5 - Valores da cor aparente proveniente dos três pontos de monitoramento do Córrego Pirapitinga no município de Ituiutaba (MG).

\begin{tabular}{c|c|c|c}
\hline \multirow{2}{*}{$\begin{array}{c}\text { Pontos de Coleta } \\
\text { de Amostras de }\end{array}$} & \multicolumn{3}{|c}{$\begin{array}{c}\text { Cor Aparente } \\
\text { (uH) }\end{array}$} \\
\cline { 2 - 4 } Água & $\begin{array}{c}\mathbf{1 .}^{\text {a }} \text { Coleta } \\
\mathbf{2 7 / 0 3 / 2 0 1 2}\end{array}$ & $\begin{array}{c}\mathbf{2 .}^{\text {a }} \text { Coleta } \\
\mathbf{0 1 / 0 7 / 1 2}\end{array}$ & $\begin{array}{c}\mathbf{3 .}^{\text {a }} \text { Coleta } \\
\mathbf{0 5} / \mathbf{1 1} \mathbf{2 0 1 2}\end{array}$ \\
\hline 1 (IFTM) & 20,02 & 27,05 & 76,06 \\
\hline 2 (Ponte) & 23,54 & 36,03 & 119,05 \\
\hline 3 (Ponte Aterro) & 30,08 & 43,02 & 215,07 \\
\hline 4 (Nascente) & 12,45 & 18,13 & 25,00 \\
\hline
\end{tabular}

Fonte: Elaboração dos autores. 
Analisando-se os valores da cor aparente apresentados na Tabela 5, obtidos através das análises da água dos quatro pontos de amostragens do Córrego Pirapitinga, indicam que todas as amostras analisadas na primeira e segunda coletas encontram-se de acordo com o valor máximo permitido pela Resolução CONAMA 357 de 2005, que determina como valor máximo de cor da água em $75 \mu \mathrm{H}$.

$\mathrm{Na}$ terceira coleta observou-se que as amostras recolhidas nos pontos 1, 2 e 3 estão acima do valor estipulado pela legislação. Possivelmente, a cor observada nas águas analisadas na segunda e terceira coletas devem-se ao carreamento de matéria orgânica presentes nas margens devido a uma maior incidência de chuva. Comparando-se a cor aparente entre as segundae terceira coletas, nota-se que há um maior valor encontrado na terceira coleta. Isto se deve principalmente a um período mais chuvoso, novembro 2012. No mês de maior precipitação (novembro) houve um aumento nos valores da cor, sendo o ponto da amostra três (Ponte Aterro) o que apresentou maior valor, provavelmente devido à presença de um lixão nas proximidades, e o carreamento de matéria orgânica e chorume para o córrego.

\subsection{Condutividade}

A condutividade elétrica é caracterizada pela expressão numérica da capacidade da água conduzir corrente elétrica, sendo uma função entre a temperatura e a concentração iônica, indicativo de quantidade de sais na amostra, e é uma medida indireta da concentração de poluentes. De acordo com a CETESB (2008), valores de condutividade elétrica superiores a $100 \mu \mathrm{S} / \mathrm{cm}$ indicam ambientes impactados. A Resolução CONAMA 357 de 2005 não estabelece limites legais para o parâmetro condutividade. Consoante a Companhia de Tecnologia de Saneamento Ambiental (2001), a condutividade é uma expressão numérica da capacidade de uma água conduzir a corrente elétrica, que depende das concentrações iônicas e da temperatura e indica a quantidade de sais existentes na coluna d'água, e, portanto, representa uma medida indireta da concentração de poluentes. Em geral, níveis superiores a 100 $\mu \mathrm{S} / \mathrm{cm}$ indicam ambientes impactados.

A condutividade de uma água permite avaliar o seu grau de mineralização, podendo resultar da lixiviação de solos (com sais como carbonatos, sulfatos, cloretos, nitratos, solúveis de cálcio, sódio e potássio, entre outros), de efluentes industriais bem como de resíduos agrícolas (MENDES; OLIVEIRA, 2004).

A distribuição dos valores da condutividade coletada nos quatro pontos avaliados encontra-se na Tabela 6, abaixo:

Tabela 6. Distribuição dos resultados de condutividade $(\mu \mathrm{S} / \mathrm{cm})$ nos pontos de monitoramento dos cursos d'água avaliados.

\begin{tabular}{|c|c|c|c|}
\hline \multirow{2}{*}{$\begin{array}{c}\text { Pontos de Coleta } \\
\text { de Amostras de } \\
\text { Água }\end{array}$} & \multicolumn{3}{|c|}{$\begin{array}{c}\text { Condutividade } \\
(\mu \mathrm{S} / \mathrm{cm})\end{array}$} \\
\hline & $\begin{array}{c}1 .^{\text {a } \text { Coleta }} \\
27 / 03 / 2012\end{array}$ & $\begin{array}{l}2^{a} . \text { Coleta } \\
01 / 07 / 12\end{array}$ & $\begin{array}{c}\text { 3. }^{\text {a }} \text { Coleta } \\
05 / 11 / 2012\end{array}$ \\
\hline 1(IFTM) & 62,72 & 64,98 & 74,5 \\
\hline 2(Ponte) & 61,44 & 58,72 & 83,9 \\
\hline 3(Ponte Aterro) & 59,82 & 79,68 & 80,9 \\
\hline 4(Nascente) & 35,40 & 37,98 & 38,87 \\
\hline
\end{tabular}

Fonte: Elaboração dos autores.

Analisando-se a Tabela 6 e comparando-se com dados da CETESB (2008), observa-se que em nenhum ponto de coleta excedeu a $100 \mu \mathrm{S} / \mathrm{cm}$, valor indica que o ambiente está altamente impactado. De uma forma geral observou-se que não ocorreu uma grande variação da condutividade entre as três coletas, indicando que nesse período não houve um aumento da entrada de resíduos agrícolas, bem como de esgoto doméstico. 


\section{5- Curvas analíticas utilizadas para as determinações de metais}

As curvas analíticas foram construídas com três pontos. Na Figura 2 encontra-se a curva analítica para Pb e na Tabela 7, os coeficientes de correlação para os metais analisados.

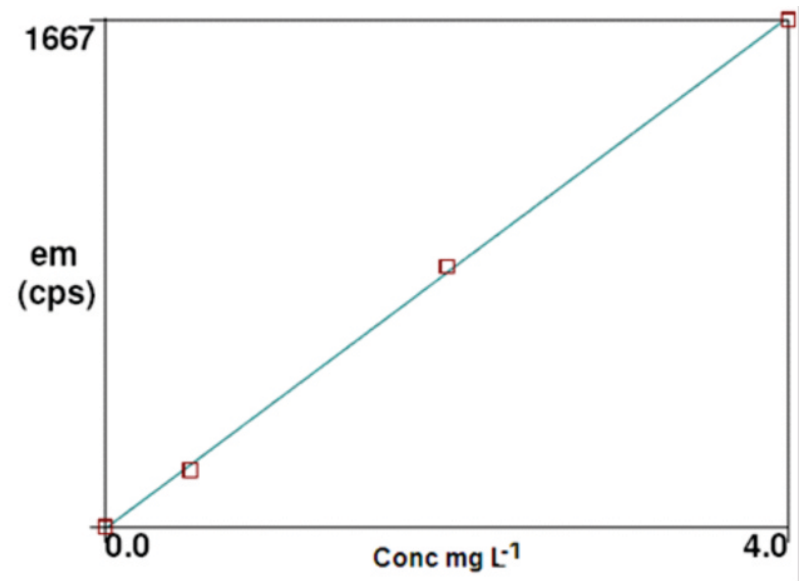

Figura 2- Curva analítica utilizada para a determinação de $\mathrm{Pb}$ em água do Córrego Pirapitinga nas proximidades do IFTM - Campus Ituiutaba (MG) .

Fonte: Elaboração dos autores.

Tabela 7. Valores dos coeficientes de correlação para as curvas analíticas dos metais

\begin{tabular}{|c|c|}
\hline Metais & Coeficiente de Correlação (r) \\
\hline Cromo & 0,999933 \\
\hline Manganês & 0,996183 \\
\hline Cádmio & 0,999946 \\
\hline Cobre & 0,999927 \\
\hline Zinco & 0,999906 \\
\hline Ferro & 0,998536 \\
\hline Chumbo & 0,998475 \\
\hline
\end{tabular}

Fonte: Elaboração dos autores.

Analisando-se os coeficientes de correlação apresentados na Tabela 7, observa-se que foram superiores a 0,99, indicando uma boa linearidade, ou seja, a resposta do detector foi linear nos intervalos de concentração empregados.

\subsection{Metais}

Neste estudo foi determinada a concentração dos metais $\mathrm{Cr}, \mathrm{Cu}, \mathrm{Cd}, \mathrm{Pb}$ e Fe em quatro pontos do Córrego Pirapitinga. A coleta foi realizada no dia 05/11/12. Na Tabela 8 estão apresentados os valores das concentrações dos metais em água para os pontos de coleta no Córrego Pirapitinga, Ituiutaba (MG). Na Tabela 9 encontra-se o limite máximo permitido pela Resolução CONAMA 357 de 2005 (BRASIL, 2005) para os metais. 
Tabela 8- Valores das concentrações dos metais em água para os pontos de coleta no Córrego Pirapitinga, Ituiutaba (MG).

\begin{tabular}{c|ccccc}
\hline $\begin{array}{c}\text { Pontos de Coleta de } \\
\text { Amostras de Água }\end{array}$ & \multicolumn{5}{c}{$\begin{array}{c}\text { Concentração de metais } \\
\left(\mu \mathbf{g ~ L}^{-1}\right)\end{array}$} \\
\hline & $\mathbf{C r}$ & $\mathbf{C u}$ & $\mathbf{C d}$ & $\mathrm{Pb}$ & $\mathrm{Fe}$ \\
1 (IFTM) & nd & nd & nd & $\mathrm{Nd}$ & nd \\
2 (Ponte) & 20,23 & nd & 1,49 & $\mathrm{Nd}$ & nd \\
3 (Ponte Aterro) & 12,69 & nd & 1,05 & $\mathrm{Nd}$ & nd \\
4 (Nascente) & 14,94 & nd & 0,48 & $\mathrm{Nd}$ & nd \\
\hline
\end{tabular}

nd- não detectável

Fonte: Elaboração dos autores.

Tabela 9 - Limite máximo permitido pela resolução 357 da CONAMA para os metais analisados.

\begin{tabular}{c|c}
\hline Metais & $\begin{array}{c}\text { Valor Máximo Permitido } \\
\left(\mathbf{m g ~ L}^{-1)}\right.\end{array}$ \\
\hline Cromo & 0,050 \\
Cádmio & 0,001 \\
Cobre & 0,009 \\
Ferro & 0,300 \\
Chumbo & 0,010 \\
\hline
\end{tabular}

Fonte: Elaboração dos autores.

Analisando-se os resultados apresentados na Tabela 8, e comparando-os com os valores determinados pela Resolução CONAMA n. ${ }^{\circ} 357 / 05$, observa-se a presença de metais $\mathrm{Cr}$ e Cd em alguns pontos de coleta, mas dentro dos limites exigidos pela Portaria.

Não há a presença dos metais $\mathrm{Fe}, \mathrm{Pb}$ e $\mathrm{Cu}$ em nenhum dos quatro pontos de coleta estudados conforme Tabela 8 . Vale ressaltar que dentre os metais citados na Tabela 9, o Cádmio destaca-se porque pode causar hipertensão, problemas nos rins e destruição dos glóbulos vermelhos. O Cromo na forma hexavalente é considerado carcinogênico, podendo causar câncer no trato digestivo e pulmões (BONI; SBAFFONI, 2009). Também a toxicidade aguda por Pb provoca várias disfunções nos rins, no sistema reprodutivo, fígado, cérebro e sistema nervoso central.

\section{3- Coliformes Fecais e Totais}

Os coliformes fecais são subgrupos das bactérias do grupo coliforme que fermenta a lactose a 44,5 \pm $0,2{ }^{\circ} \mathrm{C}$ em 24 horas. As bactérias do grupo coliforme são alguns dos principais indicadores de contaminações fecais, originadas do trato intestinal humano e de outros animais. As águas que se encontram poluídas por esses coliformes foram infectadas provavelmente pelo descarte de esgoto doméstico.

A determinação da concentração dos coliformes fecais possui grande importância como parâmetro indicativo da possibilidade de existência de micro-organismos patogênicos que são responsáveis pela transmissão de doenças de veiculação hídrica, tais como febre tifóide, cólera, entre outras (OKURA; SIQUEIRA, 2005).

Os resultados apresentados na Tabela 10 mostram que a presença de coliformes fecais e totais nos pontos de monitoramento indica que houve contaminação pelos esgotos sanitários. 
Tabela 10. Resultado das análises microbiológicas do Córrego Pirapitinga-Município de Ituiutaba (MG).

\begin{tabular}{c|c|c|c}
\hline $\begin{array}{c}\text { Pontos de Coleta de } \\
\text { Amostras de Água }\end{array}$ & Data da coleta & Coliformes Fecais & Coliforme Total \\
\hline \multirow{2}{*}{1 (IFTM) } & $01 / 07 / 2012$ & $5 \times 10^{3}$ & $1,3 \times 10^{2}$ \\
& $05 / 11 / 2012$ & $5 \times 10^{3}$ & $2,0 \times 10^{2}$ \\
\hline \multirow{2}{*}{2 (Ponte) } & $01 / 07 / 2012$ & $1,1 \times 10^{4}$ & $2,4 \times 10^{2}$ \\
& $05 / 11 / 2012$ & $8,0 \times 10^{3}$ & $8,0 \times 10^{2}$ \\
\hline \multirow{3}{*}{3 (Ponte Aterro) } & $01 / 07 / 2012$ & $2,2 \times 10^{4}$ & $1,1 \times 10^{3}$ \\
& $05 / 11 / 2012$ & $2,4 \times 10^{4}$ & $2,3 \times 10^{3}$ \\
\hline
\end{tabular}

Fonte: Elaboração dos autores .

Na Tabela 10 estão os valores de coliformes fecais e totais e a classificação segundo a Resolução do CONAMA de n. ${ }^{\circ}$ 357/05 para Classe 2, que determina que não possa exceder o limite de 1000 coliformes fecais (número mais provável em $100 \mathrm{~mL}$ de amostra) em $80 \%$ ou mais de pelo menos cinco amostras mensais coletadas em qualquer mês.

De acordo com análises microbiológicas realizadas, foram encontrados coliformes fecais e totais em todos os tubos referentes às amostras coletadas nos pontos 1,2 e 3 mostrando que as unidades formadoras de colônias ultrapassam 1.100 colônias/mL de coliforme fecais.

É sabido que a presença de $E$ coli em água ou alimentos é indicativo de contaminação por fezes humanas e também por de animais. Segundo as análises microbiológicas, a amostra do ponto 3 mostra-se imprópria para o consumo humano, por, neste ponto, verificar-se o tráfego de pessoas, animais e veículos.

Certamente a presença de altos níveis de coliformes fecais e totais neste perímetro deve-se à presença de fazendas no entorno, de um "lixão" e da entrada de gado no local, o que contribui para o resultado do estudo, porque a maior influência da urbanização e falta de infraestrutura no trecho, no qual está localizado o ponto de amostragem 3, certamente alteram o ambiente do perímetro.

Os máximos valores de coliformes totais ocorreram em coletas nos pontos 2 e 3 com valores máximos de $24.000 \mathrm{NMP} / 100$. Os coliformes fecais apresentaram o mesmo comportamento que os coliformes totais; apenas nas coletas referentes a julho de 2012, observou-se uma diminuição dos valores nos pontos 1 e 2 .

Estudo realizado por Salomão Junior (2009), em duas nascentes pertencentes ao munícipio de Muzambinho (MG), avaliou a qualidade da água dessas como impróprias para o consumo, comprovando que a atividade antrópica tem influência sobre a qualidade da água.

Compilando todos os resultados das amostras de água analisadas nos diferentes pontos do Córrego Pirapitinga, selecionadas para este estudo, observa-se que, apesar de terem sido encontrados alguns parâmetros dentro dos limites legais, é preciso que seja realizado o monitoramento em todas as fases de abastecimento da água.

De acordo com Renzetti e Dupont (2004), a responsabilidade pelo abastecimento de água com qualidade é do estado e do município, e todas as operações de tratamento e abastecimento devem ser realizadas com máximo rigor.

Dessa forma, deve-se destacar a importância do controle e monitoramento da qualidade da água para o consumo humano pelas autoridades sanitárias.

\section{Conclusão}

A partir das análises de amostras de água coletadas nos quatro pontos selecionados no Córrego Pirapitinga, coletadas em diferentes momentos desta investigação, pode-se concluir que:

Todas as amostras analisadas estavam de acordo com os padrões para consumo estabelecidos pela Resolução 357 do CONAMA, de 17 de março de 2005, exceto quanto aos parâmetros coliformes fecais e totais. A água do Córrego Pirapitinga encontra-se dentro do padrão estipulado pela Resolução 357, quanto à concentração dos metais estudados.

Algumas medidas deverão ser tomadas principalmente nos pontos críticos como no ponto 3 . Este apresentou alta concentração de coliformes, sendo que, de acordo com a Resolução 357, na água para 
consumo humano não é permitida sua presença. Diante desses resultados e considerando a importância da boa qualidade de água para consumo humano, torna-se necessário um contínuo monitoramento de todos os córregos de abastecimento público, especialmente quanto à presença de cádmio e cromo, que segundo o Relatório de Qualidade das Águas Subterrâneas do Estado de São Paulo, publicado pela CETESB entre 2004 e 2006 há uma tendência no aumento da concentração destes elementos.

A urbanização traz consigo diversas alterações no ciclo hidrológico, alterações no regime hídrico principalmente em locais onde há presença de ações humana sobre o mesmo, e devido ao crescimento acelerado gerou problemas típicos urbanos como desordenamento territorial, a falta de estrutura e equipamentos urbanos, o aumento da produção de lixo, a expansão da área urbana em direção as áreas preservadas e isto implica em alterações nos aspectos quantitativos e qualitativos das águas.

\section{Agradecimentos}

À Fundação de Amparo à Pesquisa do Estado de Minas Gerais (FAPEMIG), pelo apoio concedido para a execução deste trabalho.

\section{Surveillance and control of water quality of the stream in the village of Pirapitinga Ituiutaba (MG)}

\section{Abstract}

Water intended for human consumption must meet the minimum conditions that can be ingested, which is achieved by the treatment. The present study aimed to analyze and verify the water quality of the stream Pirapitinga city Ituiutaba (MG), about the physical, chemical and microbiological. Water samples were collected from four points, three in a stream Pirapitinga and a lower east side. Analyses of the metals $\mathrm{Cr}, \mathrm{Cd}, \mathrm{Cu}$, Fe and $\mathrm{Pb}$ were performed using the induced plasma spectroscopy technique - (ICP-OES). The analyses of color and turbidity were performed using spectrophotometric method. The results of metal, color, $\mathrm{pH}$, turbidity, temperature, fecal coliforms were compared with the values established by CONAMA Resolution 357 of 2005. It should be emphasized that from the results there is a need for continuous monitoring of the water stream Pirapitinga - Ituiutaba (MG) for the presence of $\mathrm{Cd}$ and $\mathrm{Cr}$, and fecal coliforms.

Keywords: Water quality. Physical and chemical parameters. Microbiological. Stream Pirapitinga.

\section{Referências Bibliográficas}

AMERICAN PUBLIC HEALTH ASSOCIATION - APHA. Standart methods for the examination of water and wastewater. 21. ed., New York, 1998

BETTEGA, J. M. R.; et al. Métodos analíticos no controle microbiológico da água para consumo humano. Revista Ciência Agrotécnica, Lavras, v. 30, n. 5, p. 950-954, set.-out. 2006.

BRANCO, S. M. Aspectos institucionais e legais do controle da poluição. In: Hidrologia Ambiental. São Paulo: Associação Brasileira de Recursos Hídricos/Edusp. 1991. p. 349-373.

BRASIL. Ministério do Meio Ambiente, Conselho Nacional do Meio Ambiente-Conama, Resolução n. ${ }^{\circ}$ 357 de 17 de março de 2004. Dispõe sobre os procedimentos e responsabilidades relativos ao controle e vigilância da qualidade da água para consumo humano e seu padrão de potabilidade. Diário Oficial [da] República Federativa do Brasil, Brasília (DF), 2004.

BRITO, N. M.; et al. Validação de métodos analíticos: estratégia e discussão. Pesticidas: revista de ecotoxicologia, v. 13, p. 129-146, 2005. 
BONI, M. R.; SBAFFONI, S.The potential of compost-based biobarriers for $\mathrm{Cr}$ (VI) removal from contaminated groundwater: Columntest. Journal of Hazardous Materials, v. 166, p. 1087-1095, 2009.

COMPANHIA DE TECNOLOGIA DE SANEAMENTO AMBIENTAL (CETESB) Qualidade das Águas Interiores do Estado de São Paulo - Apêndice A: significado ambiental e sanitário das variáveis de qualidade das águas e dos sedimentos e metodologias analíticas de amostragem, 2008. Disponível em: <http://www.brasil.sp.gov.br>. Acesso em: jun. 2010.

Variáveis de qualidade de águas. 2001. Disponível em: <htpp://www.ceteb.sp.gov.br/

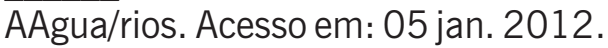

COELHO, D. A.; et al. Avaliação da qualidade microbiológica de águas minerais comercializadas em supermercados da cidade de Alfenas (MG). Revista Higiene Alimentar, São Paulo, v. 21, n. 151, p. 88-92, maio 2007.

FERNANDEZ, A. T.; SANTOS, V. C. Avaliação de parâmetros físico-químicos e Microbiológicos da água de abastecimento escolar, no município de Silva Jardim (RJ). Revista Higiene Alimentar, São Paulo, v. 21, n. 154, p. 93-98, set. 2007.

SALOMÃO JUNIOR, C. Avaliação de projeto de recuperação e conservação de nascente no município de Muzambinho (MG). 2009, 35 f. Dissertação. (Trabalho de conclusão de curso Tecnólogo em cafeicultura). Instituto Federal de Educação, Ciência e Tecnologia do Sul de Minas, Muzambinho, 2009.

MACÊDO, J. A. B. . Águas \& Águas. Belo Horizonte (MG): CRQ (MG), 2004. 977 p.

MENDES, B; OLIVEIRA, J. F. S. Qualidade da água para consumo humano. Lisboa: Editora Técnicas, 2004.

NIKAIDO, M; et al. Analysis of Bacteria, parasites and Heavy Metals in Lettuce (lactuca sativa) and Rocket Salad (Eruca sativa L $>$ ) Irrigated with Treated Effluent from a Biological Wastewater Treatment Plant. Biological Trace Element Research. 2009. Doi 10.1007/s12011.

OKURA, M. H.; SIQUEIRA, K. B. Enumeração de coliformes totais e coliformes termotolerantes em água de abastecimento e de minas. Revista Higiene Alimentar, São Paulo, v. 19, n. 135, p. 86-91, set. 2005.

RENZETTI, S.; DUPONT, D. The performance of municipal water utilities: Evidence on the role or nership. Journal Toxicology Environmental Health, v. 1861, p 20-22, 2004.

SOARES, S. R. A.; BERNARDES, R. S.; CORDEIRO NETTO, O. M. Relações entre saneamento, saúde pública e meio ambiente: elementos para formulação de um modelo de planejamento em saneamento. Revista Caderno de Saúde Pública, Rio de Janeiro, v. 18, n. 6, p. 1713-1724, nov.-dez. 2002.

TEIXEIRA, J. C. Vigilância da qualidade da água para consumo humano - utopia ou realidade? Estudo de caso: Juiz de Fora. Rio de Janeiro: Associação Brasileira de Engenharia Sanitária e Ambiental, 2005. p. 14.

UNITED STATES ENVIRONMENTAL PROTECTIO AGENCY - USEPA. Acid digestion of waters for total recoverable or dissolved metals for analysis by FLAA or ICP Spectroscopy. 1992. Disponível em: < http://www.epa.gov/epaoswer/hazwaste/test/3_series.htm>. Acesso em: 22 dez. 2011.

VON SPERLING, M. Introdução à qualidade das águas e ao tratamento de esgotos. 3. ed. Belo Horizonte: UFMG, 2005. v. 1. 452 p.

Histórico Editorial

Recebido em: 13/01/14

Aceito em: 24/03/14 